\title{
Electrostatic Separation System For Recyclable Material
}

\author{
${ }^{1}$ Prof.Vijaykumar Bhanuse, ${ }^{2}$ Madhura Suryawanshi, ${ }^{3}$ Omkar Kachare, ${ }^{4}$ Prof. Rajendra Patel. \\ Department of Instrumentation Engineering, \\ Vishwakarma Institute of Technology, Pune \\ Pune [MH], INDIA. \\ Email-vijaykumar.bhanuse@vit.edu,omkar.kachare17@vit.edu,Rajendra.patel@vit.edu
}

\begin{abstract}
Due to large demand for plastic products large of plastic waste are being generated. All of these plastic waste contains plastic, paper, cardboard, and containers made up of plastic which generate environmental pollution and it is dangerous. This paper presents electrostatic phenomenon for plastic recycling area. The performance of electrostatic separation process depends on a multiple of factors such as characteristics of the MSW material to be sorted, the applied high voltage, and the environmental conditions. The separation system receives municipal solid waste containing a mixture of MSW recyclable materials. The separation screen receive MSW recyclable materials from dumping ground. In separation stage, an electrostatic emitter is positioned adjacent to a conveyor for applying electrostatic charge on MSW recyclable materials. Conveying systems and method for detecting the presence of static electric charge in MSW material. The particles are separately collected according to their electrical properties.
\end{abstract}

Keywords - electrostatic emitter, MSW material, recyclable material.

\section{INTRODUCTION}

The generation and scrapping waste in large quantities has created a greater concern over time for the world which is for human lives and environmental conditions. Separation of waste is important for proper disposal of huge amount of garbage. Modern society produces an environmentally waste contain different types of plastic. The common method of disposable of the municipal solid waste is uncontrolled and unplanned, and exposed waste at the river sites and open areas. This method is injurious to plants, human health and animal life[1].

It is desirable to separate certain types of recyclable municipal solid waste from other types of recyclable or non recyclable waste. Recyclable municipal solid waste materials may includes plastic films, paper, plastic and other material. All this MSW materials are relatively flat, thin and flexible, lightweight and have a wide variety of different widths and Lengths[1]. Even standard inch piece of paper can be folded or crinkle by the time they arrive at recycling center. Recycling of plastic under all these conditions is possible using electrostatic phenomenon which is relatively easy than other techniques. So here we purposely used electrostatic phenomenon. The electrostatic effect consists of electric charge with opposite signs at the contact of two surface associate to different surface. This contact can occur at solidsolid, liquid-liquid or solid-liquid. For dissimilar solids which are uncharged initially, a transfer of a little electric charge takes place from one material to other as they make contact. The two materials become oppositely charged. The surface acquires a electric charge which result an electric field made between them.

For effective recycling there are different methods for plastic waste sorting. Manual sorting is suitable when plastic component are present in a large amount but it can be harmful for laborers. In an automated sorting technique NIR offers big advantage among all wave sorting technique but unsuited for dark colored plastic. In air sorting lighter particles are separated from heavier once based on specific gravity [6]. Implementing separation system for various size of plastic and paper material [4]. A Conveying systems and method for detecting the presence of static electric charge on a conveyor. External static electricity sensors make measurements of static electricity on the belt's conveying surface [5]. Waste material contains in MSW which can recyclable [3]. Disadvantage over the existing system [1]. IR sensor as well as capacitive sensor can be used for segregation of plastic but it has not good results because IR sensor is unsuitable for all types of plastic [7].

\section{A. Technique}

The mixed waste is sorted based on the electrostatic sorting method. Normally the unused and waste materials are found as paper, plastic. These materials can be recycled for further use. The primary aim of objective of proposed work is to separate material such as plastic and paper. Here we use the electrostatic emitter and collector for separation of plastic.

\section{DESIGN}

\section{B. Electrostatic Emitter}

It of three parts:

1)Electrostatic generation: Here we generate high voltage using ignition coil which gives output about $8000 \mathrm{~V}$ with MOSFET swiching.

2) Static charge storing: Leyden jar with Tesla ball is used to store static charge. Leyden jar is made up from two electrodes which stores static electricity between this two electrodes. In leyden jar we place aluminium foil inside and outside on surface of glass jar. Tesla ball consists metal terminal projecting vertically through the jar lid to make contact with the inner foil. The jar charged by electrostatic generator and other surface of foil is grounded[7]. 
Available online at www.ijrat.org

3) Static charge emitter: Generated static electricity is emitted on MSW material using simple aluminium brushes without contact to the conveyor.

\section{Electrostatic Detector}

It is used to detect presence of static charge in plastic and paper waste material. Presence of charge in the MSW material is indicated by electrostatic detector. [4]

\section{DESIGN AND IMPLEMENTATION}

D. Block Digram

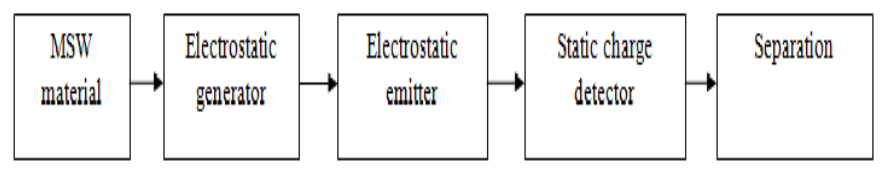

Fig. 1.1 Block Diagram

The block diagram shown in below fig. represents the separation system for recyclable material using electrostatic phenomenon. Where two type of materials are separated which is plastic and paper.

It contains four parts:

1) Electrostatic generator.

2) Electrostatic emitter.

3) Electrostatic detector.

4) Separator.

\section{E. Experimental Setup}

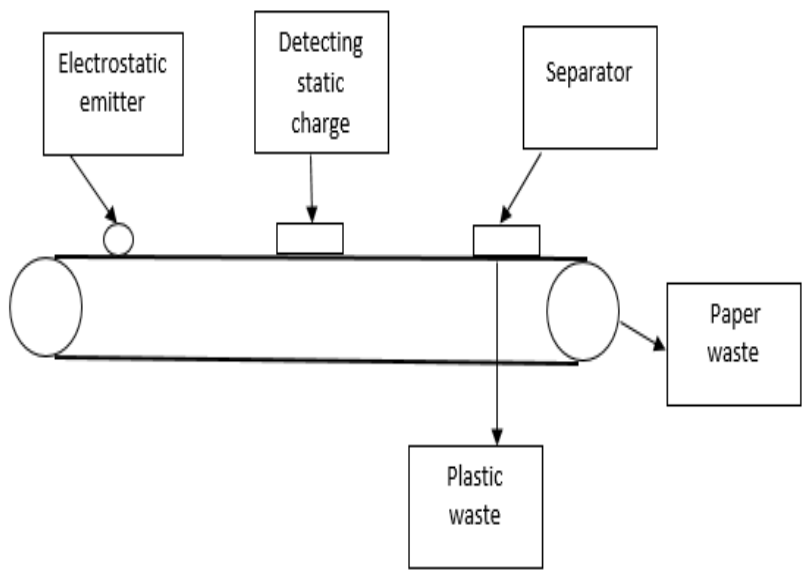

Fig. 1.2 Experimental setup

\begin{tabular}{|c|c|c|c|}
\hline \multicolumn{4}{|c|}{ Table } \\
\hline \multirow[b]{2}{*}{$\begin{array}{l}\text { SR } \\
\text { NO }\end{array}$} & \multicolumn{3}{|c|}{ Effect of static charge on materials } \\
\hline & Material & $\begin{array}{l}\text { Current } \\
\text { charge }\end{array}$ & $\begin{array}{l}\text { Lost } \\
\text { charge }\end{array}$ \\
\hline 1 & Nylon & $\begin{array}{l}\text { Positive } \\
\text { charge }\end{array}$ & $\begin{array}{l}\text { Negativ } \\
\text { e charge }\end{array}$ \\
\hline 2 & Rubber & $\begin{array}{l}\text { Negativ } \\
\text { e charge }\end{array}$ & $\begin{array}{l}\text { Positive } \\
\text { charge }\end{array}$ \\
\hline 3 & Plastic & $\begin{array}{l}\text { Negativ } \\
\text { e charge }\end{array}$ & $\begin{array}{l}\text { Position } \\
\text { charge }\end{array}$ \\
\hline 4 & Paper & $\begin{array}{l}\text { Does } \\
\text { not hold } \\
\text { charge }\end{array}$ & $\begin{array}{l}\text { No } \\
\text { charge }\end{array}$ \\
\hline
\end{tabular}

Table. 1.1 Effects of static charge on material

\section{G. Flow Diagram}

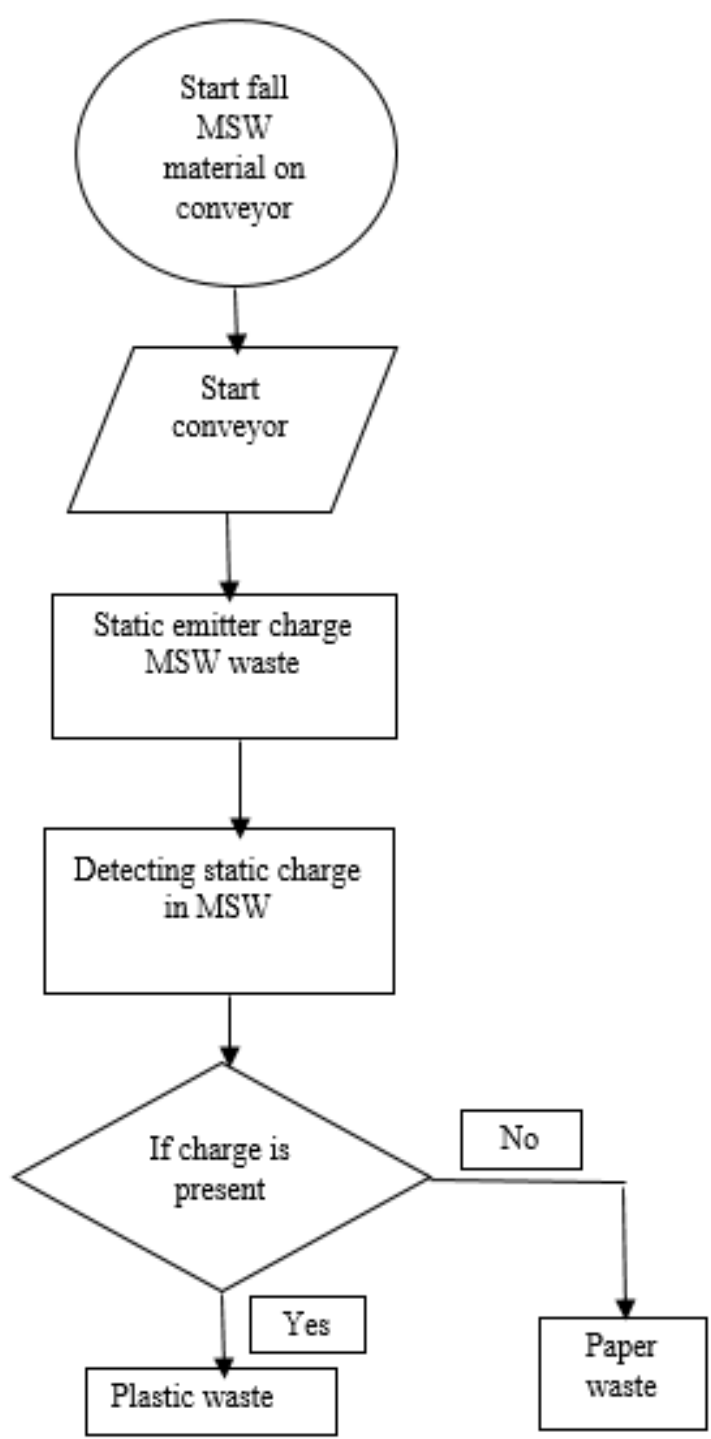

Fig. 1.3 Flow diagram of separation system 


\section{CONCLUSION}

The proposed method is a profitable solution to the current waste management problem which effectively separate paper and plastic. Separation of recyclable material effectively employs electrostatic charge used to detect presence of plastic in waste.

\section{REFERENCES}

[1] J.S. Bajaj, "Urban Solid Waste management in India", Planning Commission Government of India, New Delhi, 1995.

[2] D. Eason, B. Noble, and I.N. Sneddon, "On certain integrals of Daniel Hoornweg et al., "what a waste- A Global Review of Solid Waste Management", Urban Development \& Local Government Unit World Bank, Washington, DC., No.15, Mar. 2012.

[3] H. maehata, et. al, "Commercialization of electrostatic remover for waste plastic", Hitachi
Recycling the waste materials has a big impact on the economic condition of the country since recycling of plastic can reduce the manufacture of plastic using renewable resources and it also has an immense effect on the environment by effectively managing the solid waste.

[4] Steve miller, Roy miller, "Separation system for recyclable material", US, 2006.

[5] Joseph M. DePaso, Laitram, L.L.C, "Conveyor system, belt and method for measuring and controlling static electricity", US, 2012.

[6] Biswajid Ruj, Vivek Pandya, "Sorting of plastic waste for effective recycling", New Delhi, 2015.

[7] Mohammed Rafeeq, Sanjar alam, "Automation of plastic, metal and glass waste material segregation using arduino in scrap industry", karnataka, India 